\title{
CERVICAL SPINE INJURY; CLINICAL OUTCOME OF PATIENTS TREATED WITH AND WITHOUT SURGICAL INTERVENTION.
}

1. FCPS (Neurosurgery) Assistant Professor Neurosurgery Sheikh Zaid Hospital, Rahim Yar Khan

2. FCPS (Neurosurgery) Assistant Professor Neurosurgery Nishtar Hospital, Multan

3. Medical Officer

Post graduate Registrar Nishtar Hospital, Multan

Correspondence Address: Dr. Muhammad Sohaib Anwer Assistant Professor Neurosurgery Sheikh Zaid Hospital, Rahim Yar Khan drsohaib121@gmail.com

Article received on: $11 / 08 / 2015$

Accepted for publication: 19/09/2015

Received after proof reading: $13 / 11 / 2015$

\section{INTRODUCTION}

Cervical spine injury most of the time is associated with spinal cord injury which is defined as an acute, traumatic lesion of the neural elements in the spinal canal. This is one of the most devastating events with significant morbidity and mortality, resulting in varying degree of sensory deficit, motor loss, or bladder/bowel dysfunction which may range from inconsequential symptoms at one end of the spectrum to total neurological loss below the level of injury at the other. ${ }^{1}$

Injury to cervical spine is mostly due to blunt trauma. Incidence ranged between $2 \%$ to $6 \%$ of all blunt trauma patients suffer cervical spine injury, out of which $10 \%$ to $25 \%$ may deteriorate later on. ${ }^{2}$ Reported incidence of cervical spine injury was up to $.06 \%$ population with spinal cord injury in almost $55 \%$ of the cases. ${ }^{3,4}$

Victim of this injury belong to younger age and mostly affect the male members. The effect of injury not only result in physical dependency of the individual to other family members on one part, but also whole family suffered physically, mental- ly and economically. ${ }^{5}$

Once a neurological deficit has occurred as a result of spinal injury it is often irreversible and patients who have been rendered paraplegic or quadriplegic remain so for the rest of their lives. The best treatment of this disability is that it should not occur in the first place. Hence prevention of spinal injury is the mainstay of the management which in turn will decrease the overall burden on hospital and community.

With a lot of work in recent times and recent advances in cervical spine instrumentation and surgical techniques, surgical treatment is now most commonly advised to patients with cervical spine fractures. While the consequences of Conservative treatment can lead to post traumatic instability and chronic pain, which can be a constant source of disability. ${ }^{6}$ The main purpose of surgical treatment are to achieve maximum function, minimal pain, neurological improvement and future disability prevention. Surgery offers best restoration of anatomy, direct decompression of neural elements, early mobilization and less nursing 
care problems. ${ }^{7}$ The controversies are now mostly about the approach used: anterior, posterior or combined approaches.

In recent years anterior approach is gaining popularity. Most of the cervical spine fractures are treated with anterior approach. It is less traumatic and can directly decompress the cord, achieves better fusion rates and there is no need for adjacent segment fusion like in the posterior approach. The rate of infection in posterior approach is high, can lead to late deformity and it cannot address disrupted disk. ${ }^{8}$ However, posterior approach is used in locked facets in cases of cervical fracture dislocations and severe instability where anterior procedure alone may not be sufficient. ${ }^{9}$

In Pakistan Spinal cord injuries (SCl) are initially managed by neurosurgeons, spinal surgeons and in some cases even by orthopedic surgeons' in general surgical wards. Majority of the patients are discharged with only an advice for physiotherapy and exercises. Dedicated spine surgery centers are not present in our set up along with rehabilitation units are conspicuously missing and spinal rehabilitation consultations are rarely made. Social support systems for paraplegics are missing and a patient of $\mathrm{SCl}$ very rarely goes back to main stream society.

This study was carried out to determine the clinical outcome in terms of improvement of power in patients with cervical spine injury. Only few studies are available and most of them either emphasize on surgical or conservative management separately, here we are presenting our data regarding surgical and nonsurgical management in a developing country with reference to etiological factors, gender, age group, level of injury and initial surgical consultation.

\section{MTHODOLOGY}

This study was carried out at the neurosurgery department of Nishtar Hosptial, Multan. All new patients fulfilling the inclusion and exclusion criteria, admitted with cervical spine injury between 2010 and 2013 were included. After ethical board review from hospital ethical committee. Patient data were kept on a designed Performa. MRI performed in all patients and the Study variable included patient's demography, mode of injury, level of injury, diagnosis, neurological status, and treatment surgical and nonsurgical. Mechanism of injury was classified as road traffic accidents (RTA), falls, hit by cow and fire arm injuries. To assess power of limbs status power score used from $0-5$ at the time of admission and after discharge.

All available operated and non-operated patients were followed-up at 6 weeks, 3 months, 6 months and then yearly. The parameters noted at follow-up were the improvement in power, deterioration, hardware failure and death. Data were loaded in SPSS version 19 and analyzed for descriptive statistics and frequencies. Independent $\mathrm{T}$ test used to compare means and $\mathrm{P}$ value of $\leq$ 0.05 will be considered significant.

\section{RESULTS}

Forty three patients were included in the study. The mean age and power at the time of presentation was 33.9 and 2.26 shown in Table 1When patients divided according to age groups most of these patients were between 10-30 years as shown in table II. Most of the patients were male 31 while only 12 female Fig 1 . Regarding mechanism of injury road traffic accidents were the commonest cause of injury followed history of fall and fight shown in Table 3. When the patients were grouped according to level of injury C5-C6 found to be the most common followed by C6C7 shown in Fig 2, Table IV. Out 43 patients 29 patients underwent surgical intervention while 14 patients managed conservatively as in Table 5.When patients were followed up for a minimum period of 6 month the mean improvement in power grade was 3.3 as compared to 2.2 as in Table-l. When we compare the means of grades of power before and after treatment we found a significant difference with $P$ value of 0.00 shown in Table $I$. There were 3 deaths in our study two were in conservative and one in operative group. 


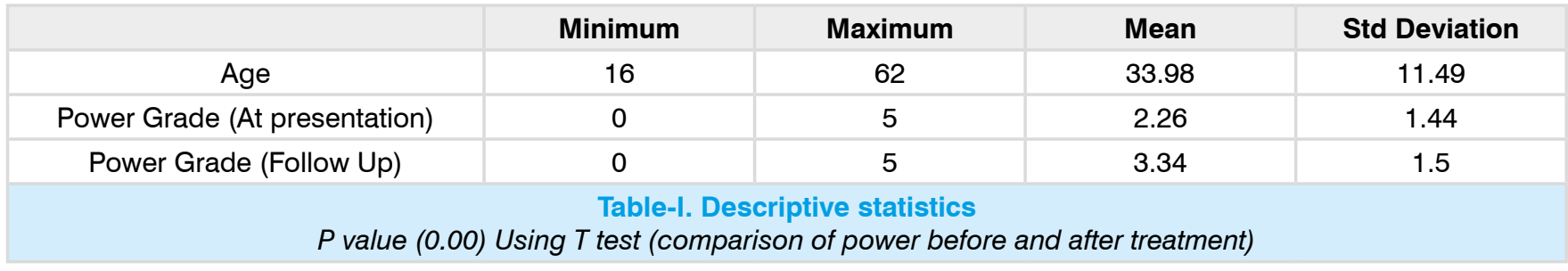

\begin{tabular}{|c|c|c|}
\hline Age Distribution & Frequency & Percentage \\
\hline $10-20$ & 20 & 46 \\
\hline $21-30$ & 12 & 28 \\
\hline $31-40$ & 7 & 16 \\
\hline $41-50$ & 3 & 8 \\
\hline $50-60$ & 1 & 2 \\
\hline Total & 43 & 100 \\
\hline
\end{tabular}

Table-II. Distribution according to Age groups

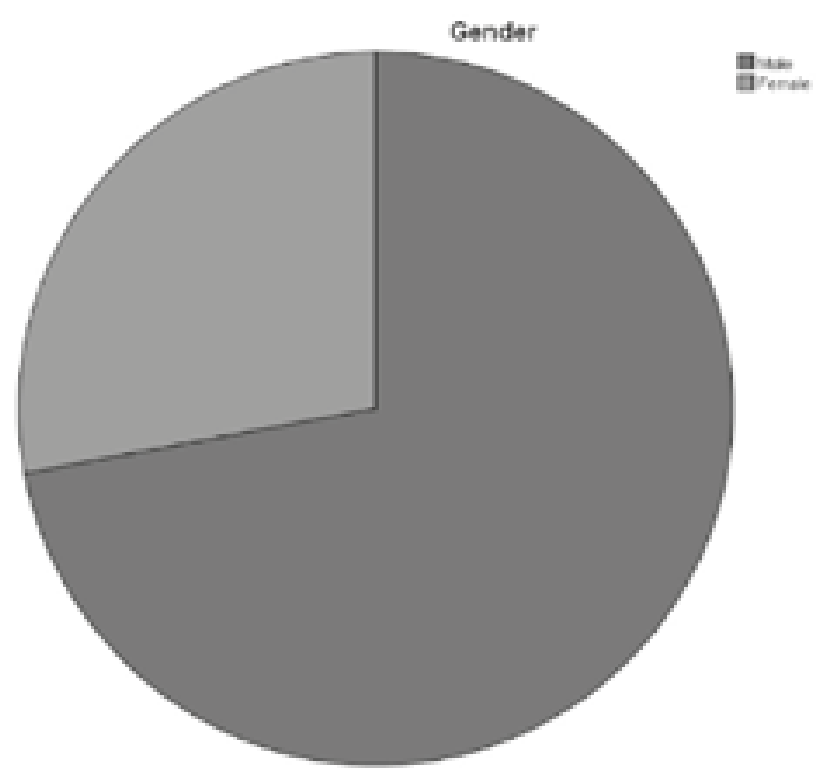

Fig-1. Gender distribution

\begin{tabular}{|c|c|c|}
\hline & Frequency & Percentage \\
\hline RTA & 20 & 46.5 \\
\hline History of fall & 12 & 27.9 \\
\hline History of fight & 5 & 11.6 \\
\hline Hit by Cow & 4 & 9.3 \\
\hline FAl & 1 & 2.3 \\
\hline Suicidal & 1 & 2.3 \\
\hline Total & 43 & 100 \\
\hline & Table-III. Mechanism of Injury \\
\hline
\end{tabular}

\begin{tabular}{|c|c|c|}
\hline Level of Injury & Frequency & Percentage \\
\hline C5-C6 & 14 & 33 \\
\hline C6-C7 & 10 & 23 \\
\hline C3-C4 & 8 & 19 \\
\hline C1-C2 & 4 & 9 \\
\hline C2-C3 & 4 & 9 \\
\hline C4-C5 & 3 & 7 \\
\hline Total & 43 & 100 \\
\hline
\end{tabular}

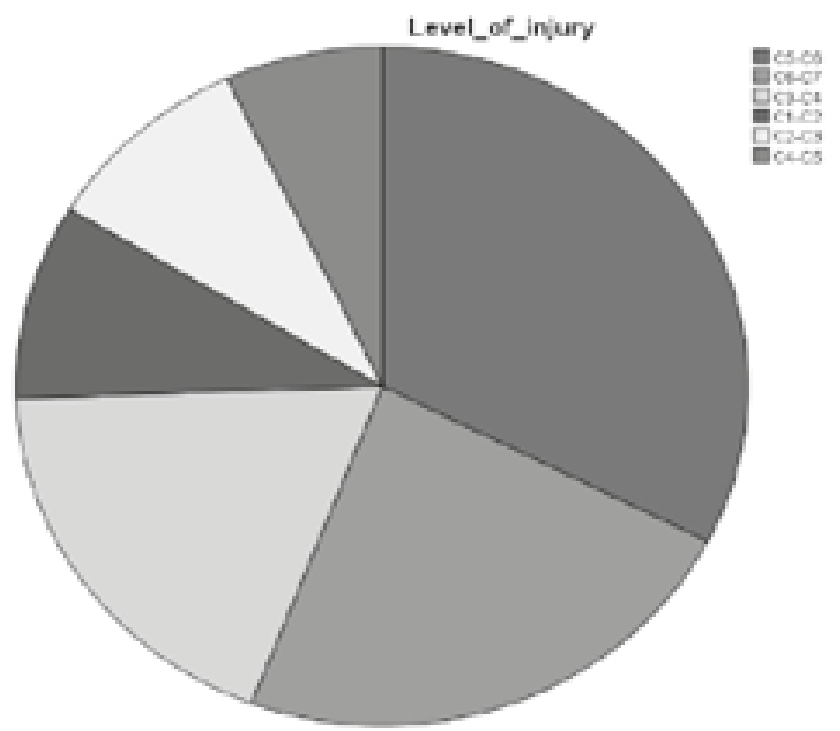

Fig-2. Distribution according to level of injury

\begin{tabular}{|c|c|c|}
\hline Treatment & Frequency & Percentages \\
\hline Surgery & 29 & 67.4 \\
\hline Conservative & 14 & 32.6 \\
\hline Total & 43 & 100 \\
\hline & Table-V. Treatment plan \\
\hline
\end{tabular}




\section{DISCUSSION}

Cervical spine injury is mostly associated with Spinal cord injury, Presents in following patterns primary and secondary. The primary pattern results in permanent damage which is due to direct mechanical impact while secondary pattern results from vascular changes, electrolyte imbalance, neurotransmitter accumulation, excito-toxicity, production of free radicals, inflammation and apoptosis. Secondary injury is preventable as if immediate necessary actions taken at appropriate time. Early Vs delayed surgical intervention is still controversial .It is seen that if secondary injury is not addressed properly it may lead to persistent compression of the spinal cord. ${ }^{10-14}$

In our study forty three patients were included. Most of the patients belong to young age group with mean age of 33.9 the results were consistent with reported series in which the mean age was 32.7..$^{15}$ As in other parts of world such as Bangladesh, Jordan and Turkey males were predominantly involved as compared to female $e^{16-18}$ which is similar to reported in our study, perhaps the male predominance is due to fact that male population is involved in outdoor work as compared to females. Male predominance is also in their most active and productive period of life are affected by spinal injury, which adds a serious economic loss to the community.

Regarding mechanism of injury in our study road traffic accidents were the commonest cause of injury followed history of fall and fight. Which is contrary to reported series from other countries like Bangladesh, India, Nigeria and Romania ${ }^{19-21}$ while in accordance with Nikunj $D$ et al ${ }^{22}$ where $80 \%$ of the patients were having history of RTA.

Regarding level of injury C5-C6 found to be the most common followed by $\mathrm{C} 6-\mathrm{C} 7$ reported in our study while in other studies sub-axial cervical fractures reported C6-7 as the most commonly fractured vertebrae, while C5-6 and C6-7 were the most common levels of dislocation. ${ }^{23}$ In our study significant improvement in power was noted which is supported by other series of Kleyn $\mathrm{P}^{24}$, Starr et $\mathrm{al}^{25}$ and Hadley et al. ${ }^{26}$

\section{CONCLUSION}

Patients presented with cervical spine injury were associated with good clinical outcome in terms of improvement of motor loss weather managed conservatively or surgically.

Copyright (C) 19 Sep, 2015.

\section{REFRENCES}

1. Solagberu BA. Spinal cord injuries in Ilorin, Nigeria. WestAfr J Med 2002;21(3):230-2.

2. Hong R, Meenan M, Prince E, Murphy R, Tambussi C, Rohrbach R, Baumann BM. Comparison of three prehospital cervical spine protocols for missed injuries. West J Emerg Med 2014; 15: 471-9.

3. Hu R, Mustard CA, Burns C. Epidemiology of incident spinal fracture in a complete population. Spine 1996; 21: 492-9.

4. Torretti JA, Sengupta DK. Cervical spine trauma. Indian J Orthop 2007; 41: 255-67.

5. Butt RM, Shams S, Habib A, Raja IA, Sarwar A, Ahmed A. Epidemiology of Spinal Injuries. Pak J Neurol 1997;3(1):20-5.

6. Fisher CG, Noonan VK, Dvorak MF. Changing face of spine trauma care in North America. Spine 2006; 31(suppl): S2-8.

7. American Association of Neurological Surgeons. Treatment of subaxial cervical spinal injuries. Neurosurg 2002; 50(suppl 3):S156-165.

8. Blauth M, Schmidt U, Bastia L, Knop C, Tscherne H. Anterior interbody fusion for cervical spine injuries-indications, implants, technique and results. ZentralblChir 1998; 123: 919-29.

9. Elsaghir $\mathrm{H}$, Bohm $\mathrm{H}$. Anterior versus posterior cervical plating in cervical corpectomy. Arch Orthop Trauma Surg 2000; 120: 549-54.

10. Dietrich WD, Chatzipanteli K, Vitarbo E, Wada K, Kinoshita $K$. The role of inflammatory processes in the pathophysiology and treatment of brain and spinal cord trauma. ActaNeurochirSuppl 2004;89:69- 74.

11. Casha S, Yu WR, Fehlings MG. Oligodendroglial apoptosis occurs along degenerating axons and is associated with FAS and p75 expression following spinal cord injury in the rat. Neuroscience 2001;103: 203-18.

12. Fehlings $M G$, Perrin RG. The role and timing of early decompression for cervical spinal cord injury: update with a review of recent clinical evidence. Injury 2005; 36 Suppl 2:B13-26. 
13. Carlson GD, Gorden CD, Oliff HS, Pillai JJ, LaManna JC. Sustained spinal cord compression: part I: time-dependent effect on long-term pathophysiology. J Bone Joint Surg Am 2003;85:86-94.

14. Yoshida H, Okada $Y$, Maruiwa $H$, et al. Synaptic blockade plays a major role in the neural disturbance of experimental spinal cord compression. J Neurotrauma 2003;20:1365-76.

15. Augutis M, Levi R. Peadiatric spinal cord injury in Sweden: Incidence, etiology and outcome. Spinal Cord 2003;41:328-36.

16. Hoque F, Grangeon C, Reed K. Spinal cord lesions in Bangladesh: An epidemiological study 1994-1995. Spinal Cord 1999;37:858-61.

17. Otom AS, DoughanAM, Kawar JS, Hattar EZ. Traumatic spinal cord injuries in Jordan: An epidemiological study. Spinal Cord 1997;35:253-5.

18. Karamehmetog SS, Nas K, Karacan I, Sarac AJ, Koyuncu H, Ataog S, Erdogan F. Traumatic spinal cord injuries in Southeast Turkey: An epidemiological study. Spinal Cord 1997;35;531-3.

19. Soopramanien A. Epidemiology of spinal injuries in Romania. Paraplegia 1994;32:715-22.
20. Chacko V, Joseph B, Mohanty SP, Jacob T. Management of spinal cord injury in a general hospital in rural India. Paraplegia 1986;24:330-5.

21. Okonkwo CA. Spinal cord injuries in Enugu, Nigeria: Preventable accidents. Paraplegia 1988;21:12-8.

22. Nikunj D, Maru MS. The functional and neurological outcome in cervical spine injuries. Internet $\mathrm{J}$ OrthopSurg 2009;17:2-7.

23. Raniga SB, Menon V, Al Muzahmi KS, Butt S. MDCT of acute subaxial cervical spine trauma: a mechanism-based approach. Insights Imaging 2014; 5: 32138.

24. Kleyn P. Dislocations of the cervical spine: closed reduction under anaesthesia. Paraplegia 1984;22:27181.

25. Starr A, Jones A, Cotler J, Balderston R, Sinha R. Immediate closed reduction of cervical spine dislocations using traction. Spine 1990;15:1068-72.

26. Hadley MN, Argires PJ. The acute/emergent management of vertebral column fracture dislocation injuries in neurological emergencies. Park Ridge, IL: The American Association of Neurological Surgeons; 1994.

\section{AUTHORSHIP AND CONTRIBUTION DECLARATION}

\begin{tabular}{|c|l|}
\hline Sr. \# & \multicolumn{1}{|c|}{ Author-s Full Name } \\
\hline 1 & Muhamamd Sohaib Anwar \\
2 & Dr. Amir Dawood Younis \\
3 & Dr. Muhammad Ali \\
\hline
\end{tabular}

Professional Med J 2015;22(11): 1504-1508.

Contribution to the paper
Study planning, designing,
Supervision of research
work. Proof reading of
manuscript
Study planning, designing
and paper writing
Data collection, Literature
review and data entry

